\title{
Effect of Density on Consolidation and Creep Parameters of Clay
}

Mustapha Mohammed Alhaji*, Musa Alhassan, Taiye Waheed Adejumo, Ramatu Jibrin

Civil Engineering Department, Federal University of Technology, PMB 65, Minna, Niger State, Nigeria

*Correspondence: E-mail: a.mustapha@futminna.edu.ng

\section{ABSTRACT}

Effect of density on consolidation and creep parameters of a clay soil was investigated using a soil classified according to Unified Soil Classification System (USCS) as Clay of High plasticity $(\mathrm{CH})$ and composing majorly of secondary minerals, including montmorillonite. The air-dried soil was compacted at five different compaction energy levels (Reduced Standard Proctor compaction energy, Standard Proctor compaction energy, West African compaction energy, Reduced Modified Proctor compaction energy, and Modified Proctor compaction energy). Specimens for consolidation tests were molded at the five different compaction energy levels (densities). The consolidation parameters (initial void ratio, compression index, and preconsolidation pressure) were observed to be empirically related to the compaction energy. The creep parameters (i.e. primary compression index, secondary compression index, and magnitude of creep) were observed to increase with increases in loading to $387 \mathrm{kN} / \mathrm{m}^{2}$, after which the values decreased. Curves resulting from these relationships were observed to increase with increases in compaction energy level and tent towards straight line at Modified Proctor compaction energy. Maximum magnitude of creep estimated for three years was observed to reduce from $455.5 \mathrm{~mm}$ at Reduced Standard Proctor compaction energy through $268 \mathrm{~mm}$ at West African compaction energy to $247.4 \mathrm{~mm}$ at Modified Proctor compaction energy levels.
ARTICLE INFO

Article History:

Submitted/Received 12 Aug 2019

First revised 14 Nov 2019

Accepted 18 Dec 2019

First available online 21 Jan 2020

Publication date 01 Mar 2020

Keywords:

Clay,

Consolidation,

Creep,

Density,

Secondary compression index,

Void ratio. 


\section{INTRODUCTION}

Density has been identified as one of the factors, affecting both physical and geotechnical properties of soils. Application of soil density was well-known and widely used before 1933 when Proctor (1933) evolved comprehensive study of remoulded density, termed Standard Proctor Compaction. Other remoulded densities, including Modified Proctor Compaction ASTM, West African Compaction, and Reduced Standard Proctor Compaction (Daniel \& Benson, 1990), were later evolved.

There the purpose of this study was to evaluated effect of density on consolidation and creep parameters of clay.

\section{REVIEW OF PAST RELATED STUDIES}

A lot of researches, aimed at studying effect of density on some physical and geotechnical properties of soils, have been carried out. Daniel \& Benson (1990) carried out intensive study on the optimal condition for stable clay liners. The geotechnical properties considered were shear strength, unit weight, shrinkage, and permeability of clay soil. These properties were evaluated at three varied compaction energy levels. The authors concluded that a density, between Reduced Standard Proctor compaction and Standard Proctor compaction gave the optimal density for stable and minimal hydraulic conductivity of clay liners. Clays have been known to form at the expense of primary rock forming minerals, which are unweathered minerals with relatively large crystals that formed under constant conditions, example mica, quartz, muscovite, and feldspar (Yatini, 2018). Daniel \& Wu (1993) carried out a study on a clay soil from Texas to evaluate the range of moisture contents and dry unit weights, at which compacted test specimen will have low hydraulic conductivity and minimal potential for shrinkage on drying and adequate shear strength.

The use of remoulded density was extended to theory and practice of achieving maximum strength and durability of clay bricks by Lopez-Lara et al. (2014). The authors worked on a trashed clay soil, stabilized with calcium hydroxide, to obtain optimum compaction energy that will give the highest Unconfined Compressive Strength (UCS), considering Standard Proctor energy level, modified Proctor energy level, and energy level of $4000(\mathrm{kN}-\mathrm{m}) / \mathrm{m}^{3}$. Yusoff et al. (2016) studied effect of compaction energy level on unit weight and UCS of kaolin-lateritic soil mixtures, at varied moisture contents. The authors considered only Standard Proctor compaction and Modified Standard Proctor compaction densities.

Effect of remoulded density on agricultural soils was also studied because of the negative effect high density has on rate of crop growth. Mada et al. (2013) worked on effect of soil compaction on soil physical properties. The properties considered were bulk density, hydraulic conductivity, and penetration resistance. Lower compaction energies of 5,10 , and 15 blows were employed.

All efforts highlighted above did not consider consolidation and creep properties of soils, which form part of the most essential geotechnical properties of clay soils. Consolidation of clay was first studied comprehensively by Terzaghi (1926), who evolved an organized and classical mathematical model to represent its progress in soils. The author defined consolidation as a decrease in water content of a saturated clay soil without replacement of same by air. This process was believed to be completed when all water in the soil pores has dissipated. However, laboratory 
experimental results have shown that deformation of soils continued after the completion of consolidation.

Buisman (1936) was the first to extend this study in detail beyond the Terzaghi (1926) about one-dimensional consolidation model. The author evolved a mathematical model presented by Eq. (1).

$$
z_{t}=\alpha_{p}+\alpha_{s} \log _{10} t
$$

Where $\alpha_{p}$ and $\alpha_{s}$ are the primary and the secondary compression index, respectively.

Gray (1936) showed that the secondary time effect, after primary consolidation, occurs in all soils, but it has more strong in organic clay soils. Taylor and Merchant (1940) were the first to develop a mathematical model, expressed by Eq. (2), which combined creep with consolidation:

$$
\frac{d e}{d t}=\frac{\partial e}{\partial t}+\frac{\partial e}{\partial p} \cdot \frac{d p}{d t}
$$

Where $e$ is the void ratio and $p$ is the vertical effective stress.

Taylor (1942) evolved a new theory, where it was pointed out that secondary compression in previous loading steps has significance influence on the next load increment. The resultant mathematical model came out as:

$$
e=e_{E o p}-C_{\alpha} \log \frac{t}{t_{100}}
$$

Where $e_{E o p}$ is the void ratio at the beginning of secondary consolidation and $C_{\alpha}$ is the slope of void ratio versus time in a semilogarithmic space.

Buisman (1936) mathematical model was changed from Koppejan (1948) to resemble Terzaghi (1926) logarithmic compression law by making the parameter to depend on logarithm of vertical effective stress. The researcher evolved a model, expressed by Eq. (4), which helps in evaluating magnitude of creep directly:

$$
\varepsilon=\frac{1}{C_{p}} \ln \left(\frac{\sigma_{v}^{1}}{\sigma_{v o}^{1}}\right)+\frac{1}{C_{s}} \ln \left(\frac{\sigma_{v}^{i}}{\sigma_{v o}^{i}}\right) \log t
$$

Where $\varepsilon, C_{p}, C_{s}, \sigma_{v 0}$, and $t$ are the magnitude of creep, the coefficient of primary consolidation, the coefficient of secondary consolidation, the surcharge pressure, and the time respectively.

Suklje (1957) pointed out that Taylor's theory A and B cannot be applied to thick clay layers. The author, therefore, assumed a parabolic excess pore pressure distribution and evaluates the rate of strain, which was put to be equal to the rate of pore water outflow. The stress-strain path was extrapolated to bigger clay thickness by approximation. Lambe (1958) argued that pore water dissipation from the micro voids is the main cause of secondary compression. Also, Nakaoka et al. (2004) and Gibson et al. (1967) concluded that secondary compression results from a local mass transfer of water between macro-pores and micro-pores. Extended equation by eliminating the small strain limitation and allowing variable compressibility and permeability of grain skeleton as well as the effect of the self-weight of the consolidating layer (Gibson et al., 1967; Terzaghi, 1926). The resulting equation came out as:

$\pm\left(\frac{\rho_{s}}{\rho_{f}}-1\right) \frac{d}{d e}\left[\frac{k(e)}{1+e}\right] \frac{\partial e}{\partial z}+\frac{\partial}{\partial z}\left[\frac{k(e)}{\rho_{f}(1+e)} \frac{d \sigma^{1}}{d e} \frac{\partial e}{\partial z}\right]+\frac{\partial e}{\partial t}=0$

Where $k$ is the coefficient of permeability.

Four different types of one-dimensional consolidation tests (i.e. constant rate of strain test, controlled gradient test, multiple stage loading test, and creep test) on five sites located within the Champlain Sea clays were conducted by Leroueil et al. (1985) as presented by Smoltczyk (2002). Results showed that the rheological behavior of these clays is controlled by two curves 


$$
\left(\sigma_{p}^{\prime}-\varepsilon_{v}\right) \text { and }\left(\frac{\sigma_{v}^{\prime}}{\sigma_{p}^{\prime}}-\varepsilon_{v}\right) \text {. }
$$

Formula for calculating creep strain was given by Mesri \& Godlewski (1977) as:

$$
\varepsilon_{c r}=\frac{C_{\alpha}}{1+e_{0}} \log _{10}\left(\frac{t}{t_{0}}\right)
$$

Where $e_{0}$ is the initial void ratio, $t_{0}$ is the initial time at which creep is assumed to start, and $\mathrm{C} \alpha$ is the secondary compression which is the slope of e-logt plot of odometer test. The authors concluded that $\mathrm{C} \alpha$ changes with change in over-consolidation ratio with its maximum occurring at $O C R=1$. Meanwhile, Alexandre (2006) showed that $\mathrm{C} \alpha$ is approximately 0.04 times the compression index $\mathrm{C}_{\mathrm{c}}$ for normally consolidated clays. A creep model, which was observed to be more general of the earlier models, was evolved as:

$$
\sigma_{d}=\sigma_{d f}(\varepsilon)+K(e) \cdot \varepsilon^{n}
$$

Considering specified stress ranges, Eq. (7) can be rewritten as:

$$
\sigma_{d}=E \dot{\varepsilon}+K \dot{\varepsilon}^{-n}
$$

The solution of the equations is given as:

$$
\varepsilon=\left(\frac{\sigma_{d}}{E}\right)-\left(\frac{K}{E}\right) \cdot \frac{1}{\left[\left(\frac{K}{\sigma_{d}}\right)^{\frac{(1-n)}{n}}+\left(\frac{1-n}{n}\right) \frac{E \cdot t^{\left(\frac{n}{1-n}\right)}}{1-n}\right.}
$$

From the vast development on the consolidation and creep theories, highlighted above, as well as the effect of density on some engineering properties of soil, this study was intended to study the effect of remoulded density on the consolidation and creep of clay soil.

\section{MATERIALS AND METHODOLOGY}

The material used for the study was a dark clay soil, collected along GwagwaladaAbuja road in Federal Capital Territory,
Abuja, Nigeria. The soil was collected at depth of between 0.5-1.0 m using disturbed sampling method. The soil was air-dried, pulverized, and prepared according to the procedure highlighted in BS 1377 (1992).

The method involved carrying out index properties test (i.e. mechanical size analysis, hydrometer analysis, liquid limit, plasticity index, specific gravity) on the clay soil to characterize the soil. All these tests were carried out using the method highlighted BS 1377 (1992). X-Ray Diffraction test (XRD) was carried out in Ithemba laboratory, Somerset West 712, South Africa. Phase characterization of the minerals and estimate of the average crystallite size of the various synthesised materials were conducted on a Bruker AXS D8 X-ray Diffractometer system coupled with $\mathrm{Cu}-\mathrm{K} \alpha$ radiation of $40 \mathrm{kV}$ and a current of $40 \mathrm{~mA}$. The $\lambda$ for K $\alpha$ was 0.1541 $\mathrm{nm}$, while the scanning rate was $1.5^{\circ} / \mathrm{min}$, operated at a stepping width of $0.05^{\circ}$ over the $2 \theta$ range.

The powder samples were placed and clipped into the rectangular aluminium sample holder. The diffractograms were recorded in the $2 \theta$ range of $20-90^{\circ}$, and the phase identification was done. The system used a time constant of $0.5 \mathrm{~s}$, a scanning step of $0.2^{\circ}$, a scanning angle range of between 20 and $90^{\circ}$, and a scanning speed of 60 second/step.

The Scherer equation shown below was used to determine the crystal size from half height peak width.

$$
d=\frac{k \lambda}{\beta \cos \theta}
$$

Where $d$ is the crystallite size in nanometer, $k$ is constant $(k=0.94), \lambda$ is the wavelength of the $X$-ray which is $0.1541 \mathrm{~nm}, \theta$ is the half- 
diffraction angle, and $\beta$ is the full width at half-maximum in radian.

Energy Dispersive Spectroscopy (EDS) test was also carried out in Electron Microscope unit, Department of Physics, Faculty of Natural Sciences, University of Western Cape, Capetown, South Africa. 0.05 $\mathrm{mg}$ of the synthesized materials sprinkled on a sample holder covered with carbon adhesive tape and were sputter coated with Au-Pd using Quorum T150T for 5 minutes prior to analysis. The sputter coated samples were characterized using Zeiss Auriga HRSEM. The secondary electron mode was activated for imaging, and homogeneous region on the sample identified. The microscope was operated with Electron High Tension (EHT) of $20 \mathrm{kV}$ for EDS and then the elemental composition of the sample was determined with EDS.

The Scanning Electron Microscopy (SEM), which visualizes morphology and microstructure of the synthesised products, was analysed using Zeiss Auriga HRSEM. 0.05 $\mathrm{mg}$ of the synthesised materials were sprinkled on a sample holder covered with carbon adhesive tape and were sputter coated with Au-Pd using Quorum T150T for 5 minutes prior to analysis. The sputter coated samples were characterized using Zeiss Auriga HRSEM. The microscope was operated with Electron High Tension (EHT) of $5 \mathrm{kV}$ for imaging. This was carried out to determine the major composition of minerals and elements, contained in the clay. The clay soil was then compacted at five different compaction energy levels: i.e. Reduced Standard Proctor compaction energy as highlighted in ASTM, Standard Proctor compaction energy as highlighted in ASTM, West African Standard compaction energy as expressed by Zhang, et al. (2013), Reduced Modified Proctor compaction energy, which has not been specified in literature, and finally the Modified Proctor compaction energy as highlighted by Jaiswal \& Lai (2016).

The Reduced Modified Proctor compaction test is similar to Modified Proctor compaction test except that the number of blows for the former is 15 , instead of 25 for latter. The procedure for carrying out X-ray Diffraction test involved crushing the clay sample. Small amount of ethyl alcohol was added to stop the hydration reaction. About $10 \mathrm{~g}$ of the grounded clay was immersed in ethyl alcohol and kept in desiccator at room temperature. The powdered sample was loaded on a sample holder. The powdered samples were scanned with an X-ray powder diffractometer using copper and potassium. The results were then displayed on a screen. The use of five different compaction energy levels was to allow for wide range of densities, whose compaction characteristics would be used to mould specimens for consolidation tests and by extension the creep tests.

One-dimensional consolidation test was carried out on the clay sample at five different densities, obtained from the five different compaction energies. The test was carried out using odometer device, fixed with stainless steel of $50 \mathrm{~mm}$ internal diameter and $20 \mathrm{~mm}$ thickness. The internal part of the ring was lubricated with silicon grease to minimize side friction between ring and the soil specimens. A filter paper of $50 \mathrm{~mm}$ diameter was placed at the top and bottom of the clay specimens to prevent the soil particles from blocking the pores of the porous stones. The method is highlighted in ASTM. Each loading was applied for 72 hours before addition of higher loads. This is to allow the consolidation test enough time for creep to set in. 


\section{RESULTS AND DISCUSSION}

\subsection{Index Properties}

Summary of result of index physical properties of the clay studied is presented on Table 1. From the results, the clay is classified as clay of high plasticity $(\mathrm{CH})$ according to Unified Soil Classification System (USCS). This type of clay has been observed to be very prone to creep settlement.

\subsection{Mineralogy of the clay}

Result of XRD test on the soil is shown on Figure 1, while SEM test result is presented on Figure 2. The major clay minerals, predominant in the sample, are quartz, ankerite, calcium silicide, montmorillonite, anorthite, kaolinite, anothoclase, and orthoclase. These minerals are similar to those observed in sensitive clay soils in literature

Table 1. Physical Properties of the Clay

\begin{tabular}{lc}
\hline Description & Quantity \\
\hline Sand (\%) & 18.4 \\
Silt (\%) & 28.9 \\
Clay (\%) & 53.0 \\
Liquid limit (\%) & 64.3 \\
Plasticity index (\%) & 35.9 \\
Specific gravity & 2.66 \\
Unified soil classification & $\mathrm{CH}$ \\
\hline
\end{tabular}

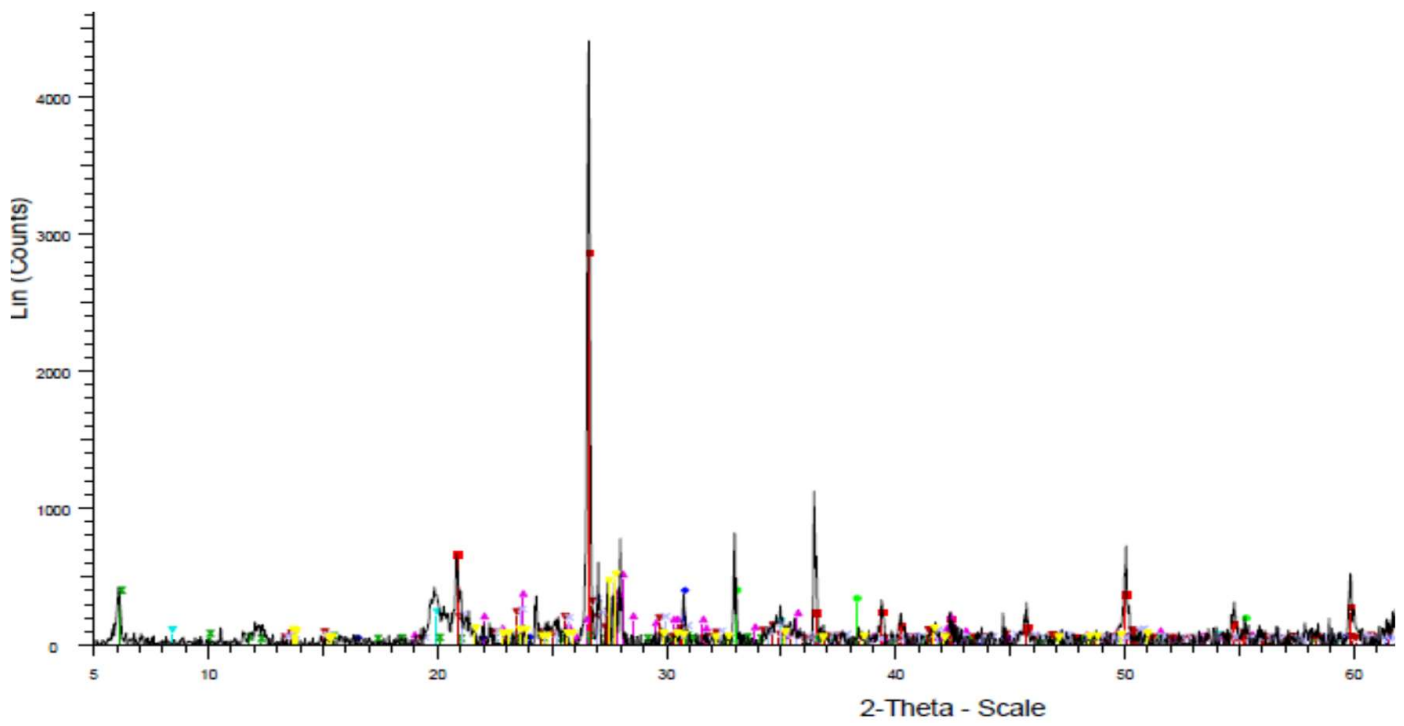

Figure 1. X-ray diffraction test result 


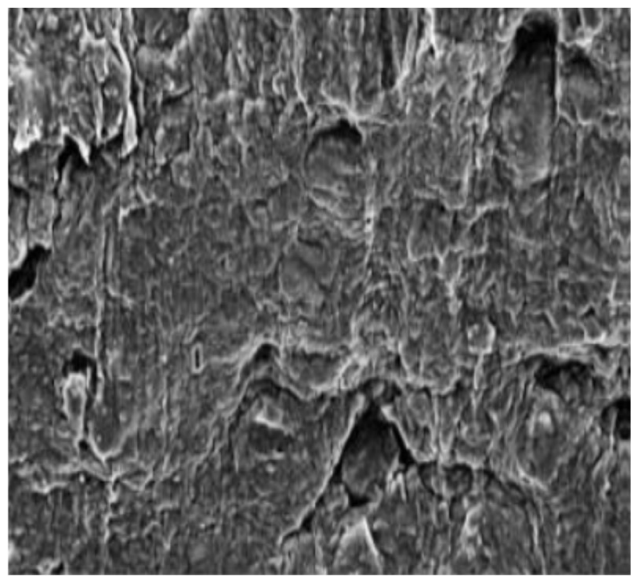

Figure 2. SEM test result

The SEM picture of clay remoulded at Standard Proctor compaction energy (Figure 2), revealed occasional presence of air voids and dense fabric of flecky clay particles similar to those presented by Zhang et al. (2013), Jaiswal \& Lai (2016), and Abdullah et al. (2018). The EDS result (see Figure 3) showed $24.9 \%$ of carbon, $39.8 \%$ of oxygen, $0.76 \%$ of magnesium, $9.8 \%$ of Aluminium, $17.4 \%$ of silicon, $0.59 \%$ of potassium, $0.54 \%$ of calcium, $0.36 \%$ of titanium, and $5.6 \%$ of iron.

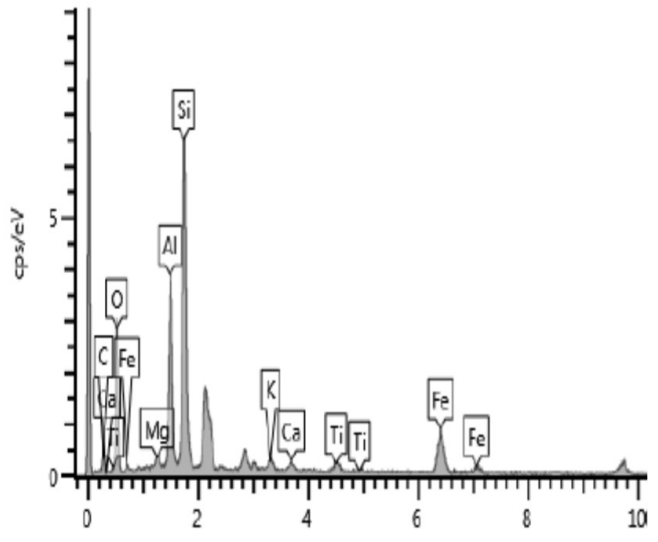

Figure 3. EDS test result

\subsection{Compaction Characteristics}

Variation of compaction characteristics with compaction energy level are shown in Figures 4 and 5, respectively, for Maximum Dry Densities (MDD) and Optimum Moisture
Contents (OMC). Table 2 shows the different compaction tests and their energies. It was observed that the MDD increased from 1.512 $\mathrm{g} / \mathrm{cm}^{3}$ (at Reduced Standard Proctor compaction) to $2.000 \mathrm{~g} / \mathrm{cm}^{3}$ (at Modified Proctor compaction), while OMC reduced from 29.1\% (at Reduced Proctor compaction energy) to $12.1 \%$ (at Modified Proctor compaction energy). These trends are in agreement with Lambe (1958) and Yusoff, et al. (2016). These authors attributed the variation to soil structure and electrical double layer theory. The phenomenon explained that the trend results from the inherent attractive Van der Waals' forces between two clay particles and a repulsive force which is due to double layers of adsorbed water trying to come into contact with each other. Addition of water will reduce the activity of the double layer, which will encourage the clay particles to be in a flocculated state thus, resulting to soft soil mass. Increases in water reduced action of the double layer around the clay particles; thus, it is resulting to particles of dispersed form, appearing dense in structure.

\subsection{Consolidation Properties}

Results of consolidation tests on samples remoulded at five different compaction energy levels are shown in Figure 6. The geotechnical properties considered in this study included compression index (Cc), preconsolidation stress $\left(\sigma_{p}\right)$, and initial void ratios $\left(\mathrm{e}_{0}\right)$. Figure $\mathbf{7}$ shows variation of compression index, which reduces with increase in compaction energy. The relationship is represented by Eq. (11).

This trend is similar to the trend of variation of initial void ratio with compaction energy (Figure 8), which can also be represented by Eq. (12): 


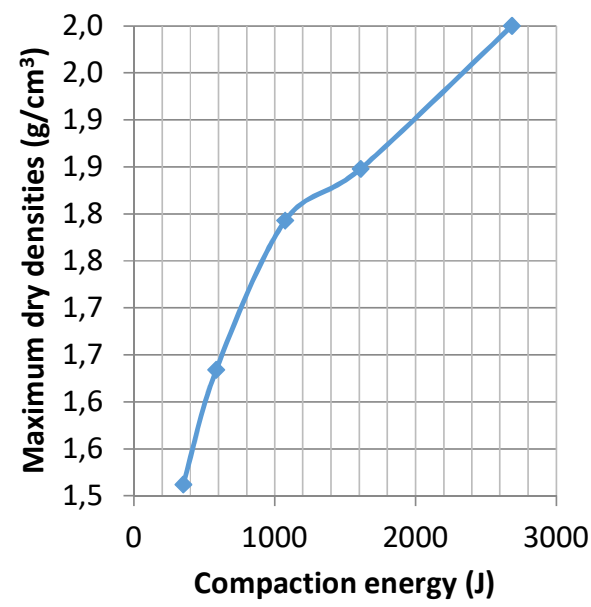

Figure 4. Variation of MDD with compaction energy

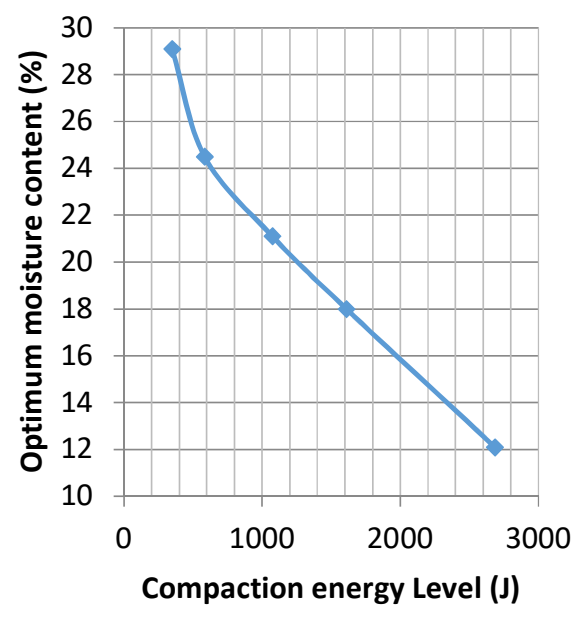

Figure 5. Variation of OMC with compaction energy

$C_{c}=-0.128 \ln ($ compaction energy $)+1.206$

$$
e_{0}=-0.217 \ln (\text { compaction energy })+2.546
$$

The trends depicted by Eqs. (11) and (12) must have resulted from the reduction in moisture with increase in compaction energy, which would continuously reduce the double layer around the clay particles, consequently put the clay more into dispersed structure, and hence offer more resistance to compressibility. The preconsolidation stress, however, increased with increases in compaction energy (see Figure 9), represented by expression:

$\sigma_{p}=0.0303 \ln ($ compaction energy $)+56.239$

Table 2. Compaction tests and their energies

\begin{tabular}{llc}
\hline S/N & $\begin{array}{l}\text { Types of compaction } \\
\text { test }\end{array}$ & $\begin{array}{c}\text { Compaction } \\
\text { energies } \\
\text { (Joules) }\end{array}$ \\
\hline 1 & $\begin{array}{l}\text { Reduced standard } \\
\text { Proctor compaction } \\
\text { test }\end{array}$ & 350 \\
2 & $\begin{array}{l}\text { Standard Proctor } \\
\text { compaction test } \\
3\end{array}$ & 585 \\
& $\begin{array}{l}\text { West African standard } \\
\text { compaction test } \\
4\end{array}$ & 1075 \\
& $\begin{array}{l}\text { Reduced modified } \\
\text { Proctor compaction } \\
\text { test } \\
5\end{array}$ & 1610 \\
& $\begin{array}{l}\text { Modified Proctor } \\
\text { compaction test }\end{array}$ \\
\hline
\end{tabular}

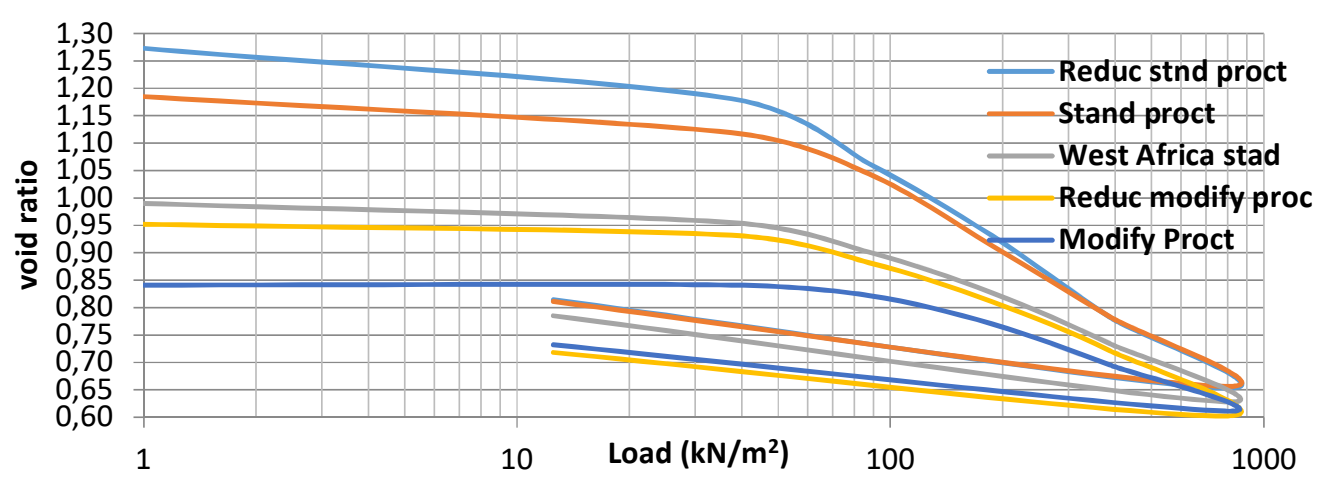

Figure 6. Void ratio-effective stress relationship for clay moulded at five compaction energies 


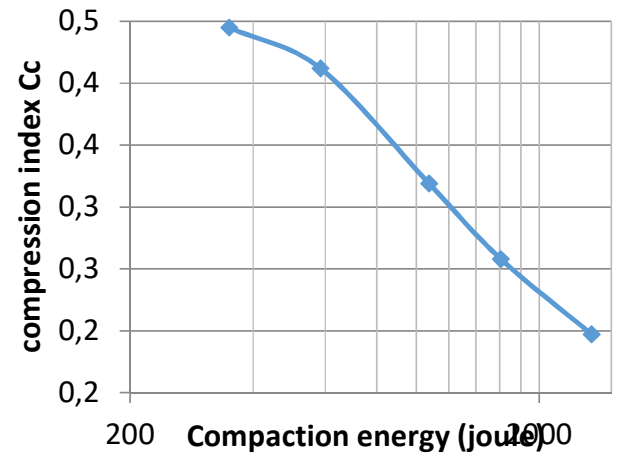

Figure 7. Variation of compression index with compaction energy

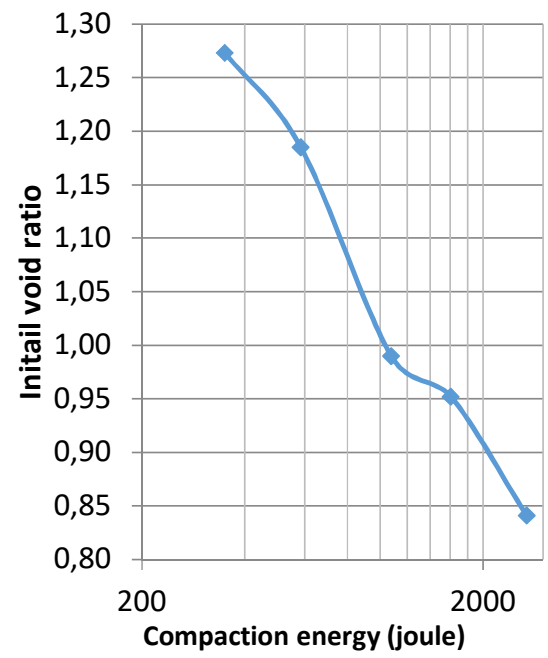

Figure 8. Variation of initial void ratio with compaction energies

The trend (depicted by preconsolidation stress) is expected since it reduced moisture results to dispersed clay structure. Therefore, lower moisture further increased the dispersed nature of the clay structure, and further it increased resistance of the clay to compression under loading. Hence, it had higher preconsolidation stress.

\subsection{Creep Properties}

The properties considered in creep were primary compression index, secondary compression index, and magnitude of creep for the varying loads and at five different compaction energy levels. Figure $\mathbf{1 0}$ shows a representative sketch with primary compression index $\left(C_{p}\right)$ and secondary compression index $\left(C_{\alpha}\right)$ as well as the time for $100 \%$ consolidation $\left(\mathrm{t}_{100}\right)$. Equation (6) was used to evaluate magnitude of creep for all the loadings at the five different compaction energy levels.

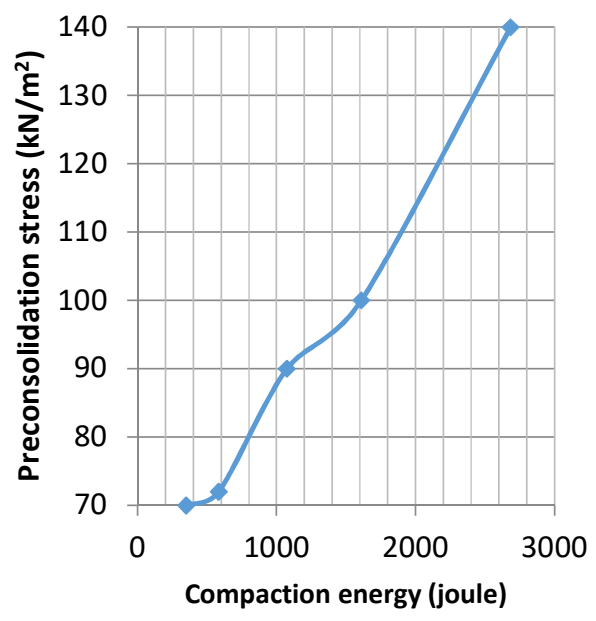

Figure 9. Variation of preconsolidation stress with compaction energies

Figure 11 presents variation of primary compression index with compaction energy. From the Figure 11, primary compression index was observed to increase from 0.19 (at $37.5 \mathrm{kN} / \mathrm{m}^{2}$ ) to a maximum of 0.581 (at $\left.187 \mathrm{kN} / \mathrm{m}^{2}\right)$, after which the values reduced to 0.492 (at $387 \mathrm{kN} / \mathrm{m}^{2}$ ) to straight out 0.465 (at $787 \mathrm{kN} / \mathrm{m}^{2}$ for Reduced Standard Proctor compaction energy). The trend in the next density (Standard Proctor compaction energy), showed increament from 0.07 (at $37.5 \mathrm{kNm}^{2}$ ) to its maximum of 0.49 (at $\left.187 \mathrm{kN} / \mathrm{m}^{2}\right)$. The values remained constant to $387 \mathrm{kN} / \mathrm{m}^{2}$, after which it increased to 0.505 (at $787 \mathrm{kN} / \mathrm{m}^{2}$ ). The trend for West African compaction energy level revealed the values increasing gently from 0.048 (at $37.5 \mathrm{kN} / \mathrm{m}^{2}$ ) to 0.462 (at $787 \mathrm{kN} / \mathrm{m}^{2}$ ). Both the Reduced Modified Proctor compaction energy and the Modified Proctor compaction followed the same trend, but it has with maximum values in reducing in compaction energy level. In 
general, the trend for each of the compaction energies with varied applied load showed a curve whose curvatures increased with increases in compaction energy level and tent towards a straight line as shown in Figure 11. These trends can be attributed to the relatively high rate of water dissipation from the clay during consolidation. At reduced Standard Proctor, the moulding water content was higher, resulting to lower dry density. This allowed only little more moisture to be absorbed into the clay mineral structure and the void spaces during the initial 24 hours soaking. This allowed only outward movement of water which continued until all water, contained in the voids were dissipated. This resulted to faster dissipation of water since there was no further absorption of water by the clay particles resulting to higher compression index. At higher compaction energy levels, like West African compaction energy, Reduced Modified Proctor compaction energy, and Modified compaction energy levels, the moulding moisture content are lower, implying that, during consolidation, the clay has more affinity for water absorption, reducing outward dissipation of water. This is probably responsible for the increases in compression index at Modified Proctor compaction energy level.

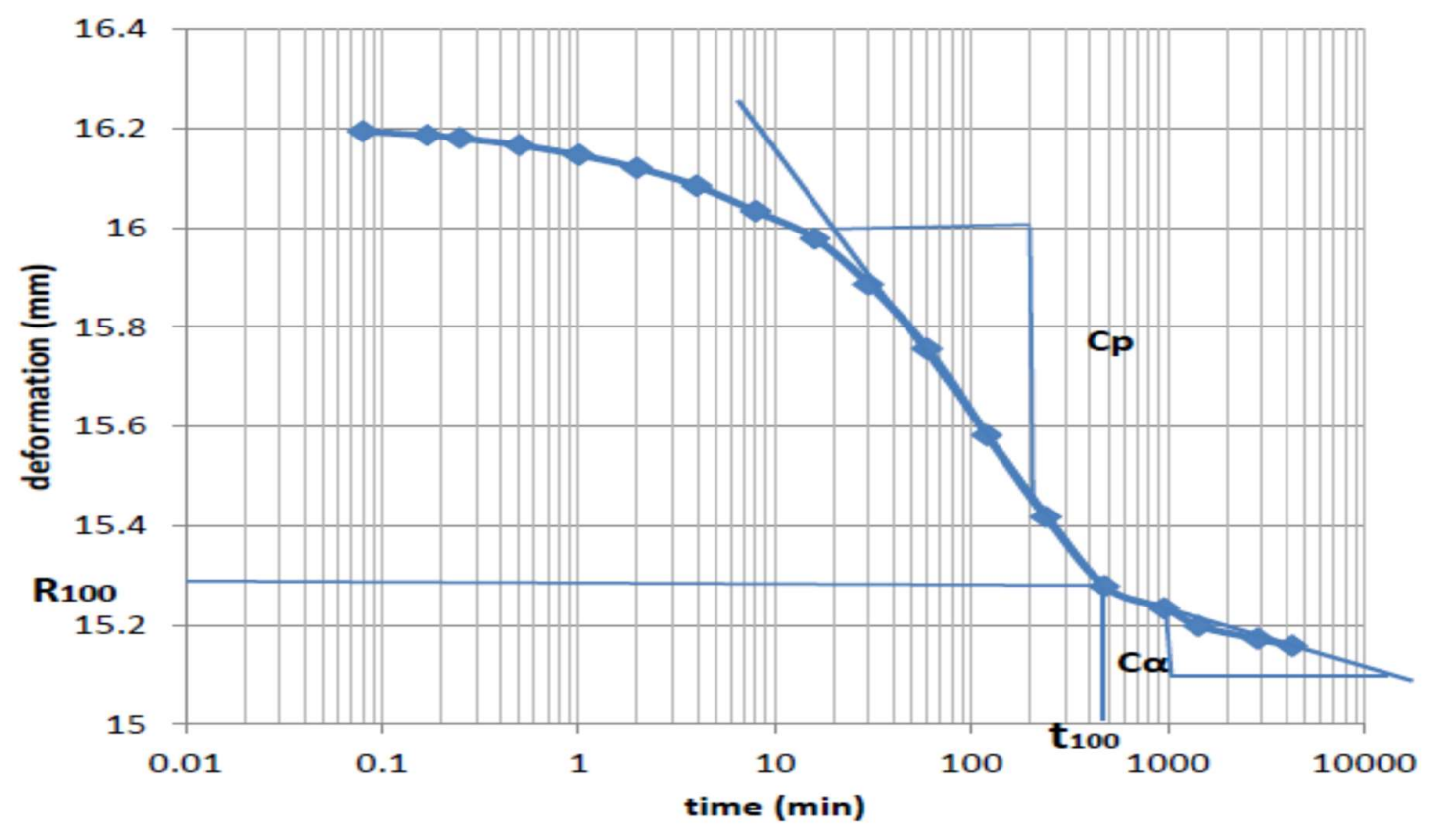

Figure 10. Sketch showing creep parameters with loading 


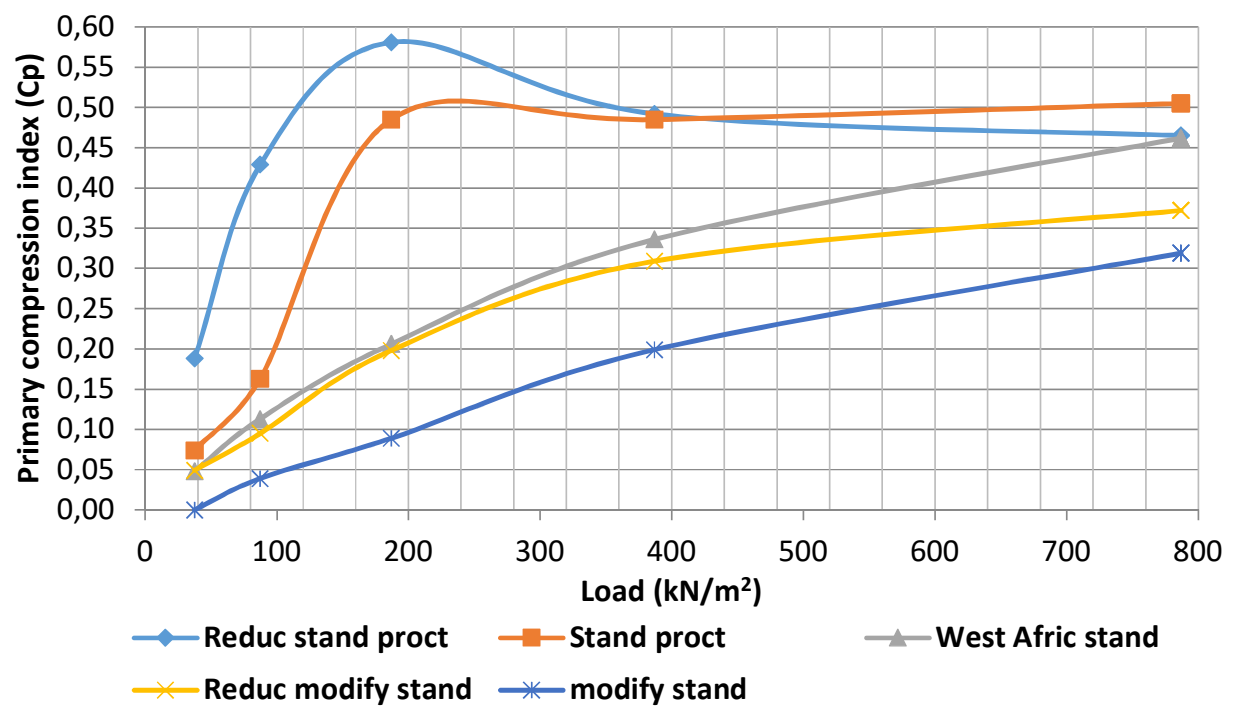

Figure 11. Variation of primary compression index with compaction energy

The trend for variation of secondary compression index and magnitude of creep with loading at varied compaction energy levels are shown in Figures $\mathbf{1 2}$ and 13, respectively. The trends are very similar since the magnitude of creep is directly a function of the secondary compression index. The values were observed to increase with increases in loading to maximum at $187 \mathrm{kN} / \mathrm{m}^{2}$, after which the values reduced. The general trend also showed curves, whose curvatures increased from Reduced Standard Proctor compaction to its maximum at Modified Standard Proctor compaction. The maximum secondary compression indicated decreament from 0.117 (at Reduced Standard Proctor compaction) to 0.078 (at West African compaction energy), through 0.069 (at Reduced Modified compaction energy level), and finally to 0.07 (at Modified Proctor compaction energy).

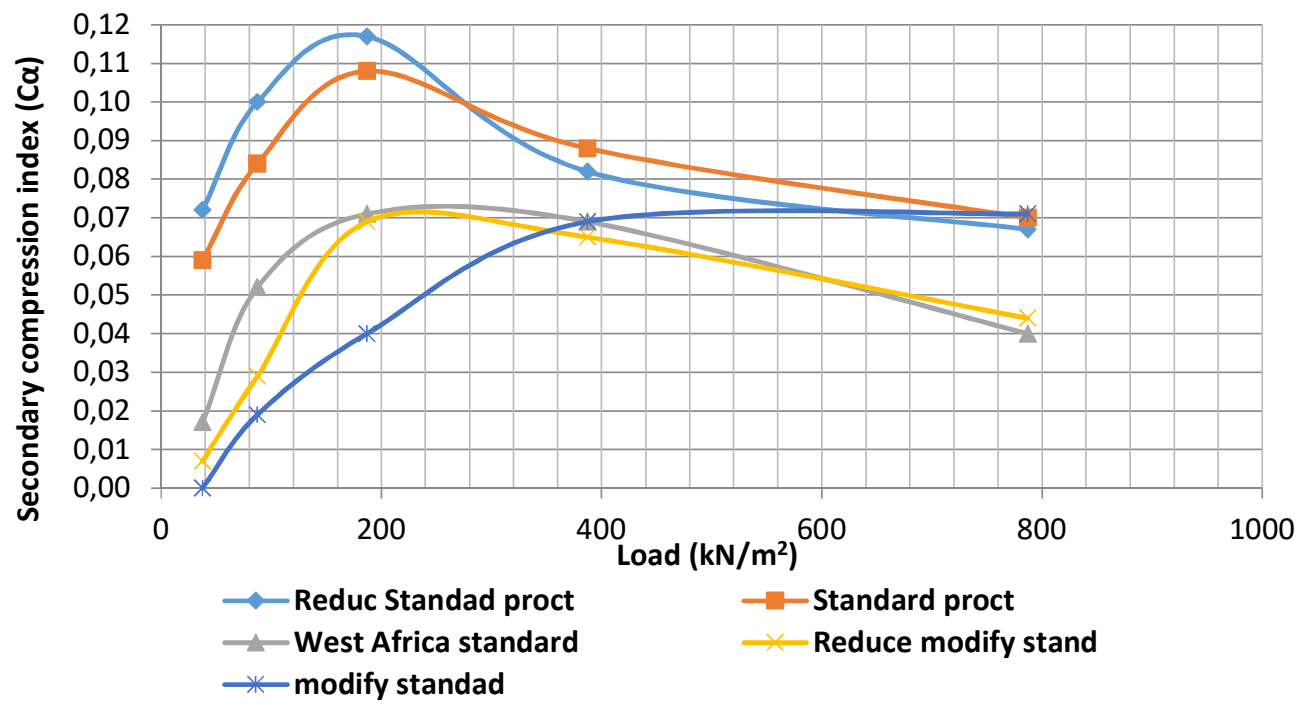

Figure 12. Secondary compression index with varied compaction energy levels 
Similarly, the maximum magnitude of creep, evaluated from Eq. (6), reduced from $455.5 \mathrm{~mm}$ at Reduced standard Proctor through $268 \mathrm{~mm}$ (at West African compaction energy) to $239 \mathrm{~mm}$ (at reduced modified Proctor compaction), and finally to $247 \mathrm{~mm}$ (at Modified Proctor compaction energy). Variation in secondary compression index with increase in loading has been shown by Larsson (1986), but author did not report any specific trend in their relationship. The trend, shown in Figure 12, probably resulted from the time resistance concept $(R)$ as observed by Jambu (1969). Since excess pore pressure is zero during creep, time can be taken as an action, and creep strain as a reaction. This leads to reduction in secondary compression index with increases in compaction energy level. The magnitude of creep for three years was evaluated using Eq. (6) for each compaction energy level at varied loading as shown in Figure 13. The magnitude of creep is proportional to the initial void ratio of the molded clay, which is the reason for the trend observed in the magnitude of creep.

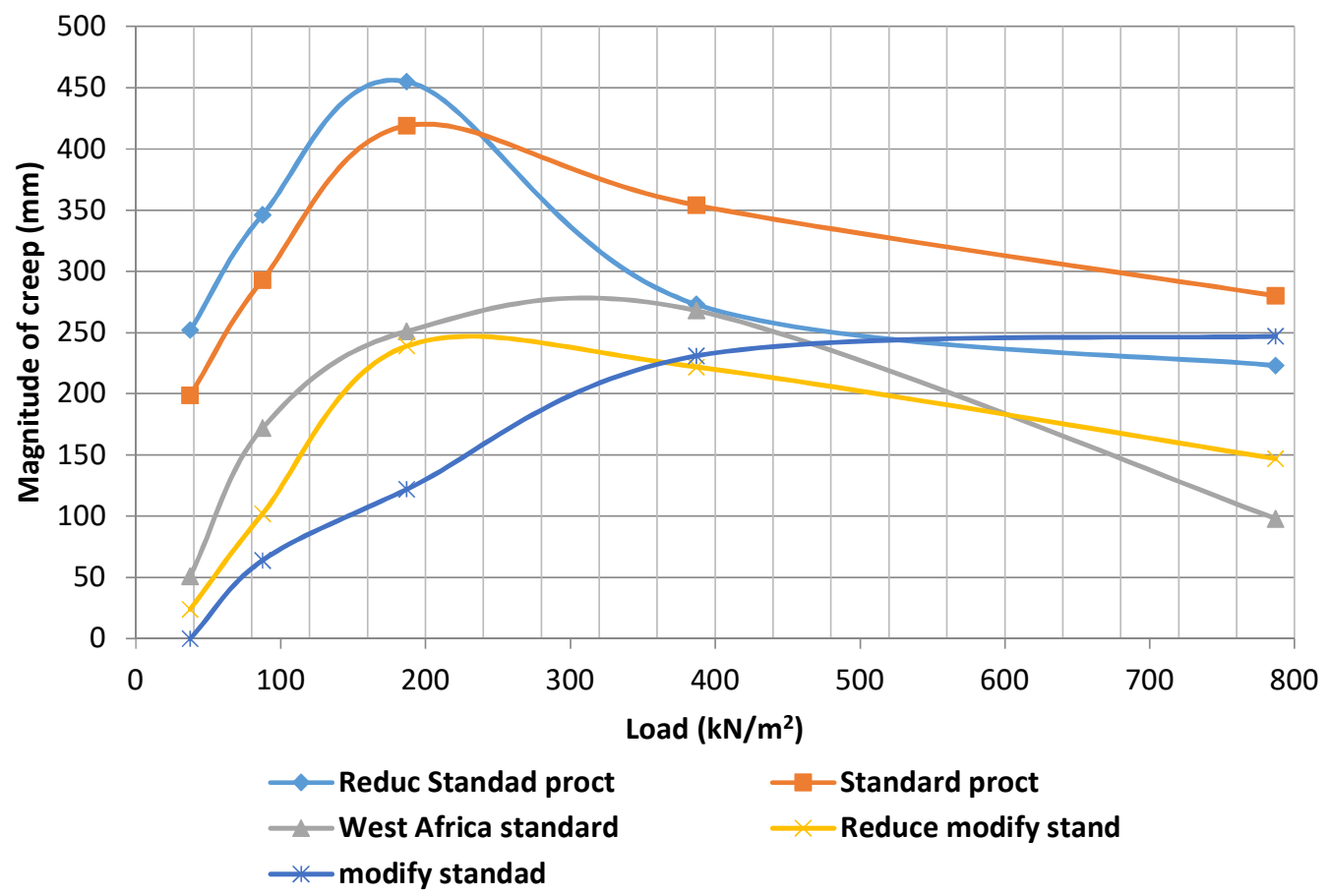

Figure 13. Magnitude of creep with varied compaction energy levels

\section{CONCLUSION}

Effect of remolded density on the consolidation and creep parameters of clay has been studied and the following conclusions were drawn:

(i) Initial void ratio, compression index and preconsolidation pressures are empirically related to compaction energy. (ii) The primary compression index at Reduced Standard Proctor compaction energy increases with increases in loading to $387 \mathrm{kN} / \mathrm{m}^{2}$, after which the values reduce. Subsequent energy levels show continuous increases in primary compression index over all the applied loadings. Curvature of the curves was also observed to increase with increases in compaction energy level towards a 
43 | Indonesian Journal of Science \& Technology, Volume 5 Issue 1, January 2020 Hal 31-44

straight line at Modified Proctor compaction energy.

(iii) The secondary compression index as well as magnitude of creep increases with increase in loading to $387 \mathrm{kN} / \mathrm{m}^{2}$, after which the values reduced. The curves, formed at position of $387 \mathrm{kN} / \mathrm{m}^{2}$ loading, increase with increases in compaction energy levels.

(iv) The maximum magnitudes of creep, estimated for future three years, were observed to reduce from $455.5 \mathrm{~mm}$ at
Reduced Standard Proctor compaction energy through $268 \mathrm{~mm}$ at West African compaction energy to $247.4 \mathrm{~mm}$ at Modified Proctor compaction energy levels.

\section{AUTHORS' NOTE}

The authors declare that there is no conflict of interest regarding the publication of this article. Authors confirmed that the data and the paper are free of plagiarism.

\section{REFERENCES}

Abdullah, H. H., Shahin, M. A., \& Sarker, P. (2018). Use of Fly-Ash Geopolymer Incoporating Ground Granulated Slag for Stabilization of Kaolin Clay Cured at Ambient Temperature, Geotechnical and Geological Engineering, 37(2), 721-740.

Alexandre, G. F. (2006). Contribution to the Understanding of the Undrained Creep. DSc. thesis, COPPE/UFRJ, Rio de Janeiro, Brazil (in Portuguese).

Buisman, A. S. K. (1936). Results of Long Settlement Tests. Proceeding of International Conference on Soil Mechanics and Foundation Engineering, 1, 103-106.

Daniel, D. E., \& Benson, C. H. (1990). Water content-Density Criteria for Compacted Soil Liners. Journal of Geotechnical Engineering, 116(12), 1811-1830.

Daniel, D. E., \& Wu, Y. K. (1993). Compacted Clay Liners and Covers for Arid Sites. Journal of Geotechnical Engineering, 119(2), 223-237.

Gibson, R. E., England, G. L., \& Hussey, M. J. L. (1967). The Theory of One- Dimensional Consolidation of Saturated Clays. 1. Finite Non- Linear Consolidation of thin Homogeneous layers. Geotechnique , 17(3), 261-273.

Gray, H. (1936). Progress Report on Research on the Consolidation of Fine- grained Soils. Proceedings of First International Conference of Soil Mechanics and Foundation Engineering Cambridge, 138141.

Jaiswal, M., \& Lai, B. (2016). Impact of Rice Husk Ash on Soil Stability (Including Micro Level Investigation). Indian Journal of Science and Technology, 9(30), 1-7.

Jambu, N. (1969). The Resistance Concept Applied to Deformation of Soils, Proceedings Seventeenth International Conference on Soil Mechanics and Foundation Engineering, 1, 191-196.

Koppejan, A. W. (1948). A Formula Combining the Terzaghi Load Compression Relationship and the Buisman secular Time Effect. Proceeding of Second International Conference of Soil Mechanics and Foundation Engineering, Rotterdam, 3, 32-37.

Lambe, T. W. (1958). The Structure of Compacted Clays. Journal of Soil Mechanics and Foundation Division, 24. 
Larsson, R. (1986). Consolidation of soft soils, Report 29. Swedish Geotechnical Institute, Linkoping.

Leroueil, S., Kabbaj, M., Tavenas, F., \& Bouchard, R (1985). Stress- Srain - Strain Rate Relation for the Compressibility of Sensitive Natural Clays. Geotechnique, 35(2), 159-180.

Lopez-Lara, T., Gonzalez-Vega, C. L., Hernandez-Zaragoza, J. B., Rojas-Gonzalez, E., Carreon-Freyre, D., Salgado-Delgado, R., Garcia-Hernandez, E., \& Cerca, M. (2014). Application of Optimum Compaction Energy in the Development of Bricks made with Construction Trash Soils. Advances in Material Science and Engineering, 2, 141-119.

Mada, D. A., Ibrahim, S., \& Hussaini, I. D. (2013). The Effect of Soil Compaction on Soil Physical Properties Southern Adamawa State Agricultural Soils. International Journal of Engineering and Science, 2(9), 70-74.

Mesri, G., \& Godlewski, P. M. (1977). Time and stress-compressibility interrelationship. ASCE J Geotech Eng Div, 103(5), 417-430.

Nakaoka, K., Yamamoto, S., Hasagawa, H., Kitayama, K., Saito, N., Ichikawa, Y., Kawamura, K., \& Nakano, M. (2004). Long Time Consolidation Mechanisms Based on Micro-Macro Behavior and Insitu XRD Measurements of Basal Spacing of Clay Minerals. Applied Clay Science, 20(4), 521-533.

Nigerian General Specification (1997). Roads and Bridges. Federal Ministry of Works, Abuja, Nigeria.

Proctor, R. R. (1933). The Design and Construction of Rolled Earth Dams. Engineering News Record, 111, 372-376.

Smoltczyk, U. (2002). Handbook of Geotechnical Engineering Practice, Berlin: Wiley-VCH.

Suklje, L. (1957). The analysis of the consolidation process by the Isotaches method. Proceeding of Fourth International Conference of Soil Mechanics and Foundation Engineering, 1, 200-206.

Taylor, D. W. (1942). Research on Consolidation of Clays. Massachusetts Institute of Technology Publication from Department of Civil and Sanitary Engineering, 82, 147.

Taylor, D. W., \& Merchant, W. (1940). A Theory of Clay Consolidation Accounting for Secondary Compression. Journal of Mathematics and Physics, 19(1-4), 167-185.

Terzaghi, K. (1926). Die Theory der hydrodynamischen Spannungserscheinungen und ihr erdbautechnisches Anwendungsgebiet (The theory of hydrodynamics stress phenomena and its application to soil mechanics). Proceedings of First International Congress on Applied Mechanics, 288.

Yatini, Y. (2018). Influence of Clay on Time Domain Induced Polarization. Indonesian Journal of Science \& Technology, 3(1), 1-10.

Yusoff, S. A. N. M., Bakar, I., Wijeyesekera, D. C., Zainorabidin, A., Azmi, M., \& Ramli, H. (2016). The Effect of Different Compaction Energy on Geotechnical Properties of Kaolin and Laterite. International Conference on Applied Physics and Engineering (ICAPE), 1875(1), 030009-1-030009-7.

Zhang, M., Guo, H., El-Korchi, T., Zhang, G., \& Tao, M. (2013), Experimental feasibility Study of Geopolymer as the Next Generation Soil Stabilizer, Construction and Building Materials, 47, 1468-1478. 